\title{
RAPID PROTOTYPING OF PATTERNED MULTIFUNCTIONAL NANOSTRUCTURES
}

Hongyou Fan, Yunfeng Lu, Gabriel P. López, and C. Jeffrey Brinker

The University of New Mexico/NSF Center for Micro-Engineered Materials, The Advanced Materials Laboratory, Sandia National Laboratories, Albuquerque, NM

\section{ABSTRACT}

The ability to engineer ordered arrays of objects on multiple length scales has potential for applications such as microelectronics, sensors, wave guides, and photonic lattices with tunable band gaps. Since the invention of surfactant templated mesoporous sieves in 1992, great progress has been made in controlling different mesophases in the form of powders, particles, fibers, and films. To date, although there have been several reports of patterned mesostructures, materials prepared have been limited to metal oxides with no specific functionality. For many of the envisioned applications of hierarchical materials in micro-systems, sensors, waveguides, photonics, and electronics, it is necessary to define both form and function on several length scales. In addition, the patterning strategies utilized so far require hours or even days for completion. Such slow processes are inherently difficult to implement in commercial environments. We present a series of new methods of producing patterns within seconds. Combining sol-gel chemistry, Evaporation-Induced Self-Assembly (EISA), and rapid prototyping techniques like pen lithography, ink-jet printing, and dip-coating on micro-contact printed substrates, we form hierarchically organized silica structures that exhibit order and function on multiple scales: on the molecular scale, functional organic moieties are positioned on pore surfaces, on the mesoscale, mono-sized pores are organized into 1-, 2-, or 3-dimensional networks, providing size-selective accessibility from the gas or liquid phase, and on the macroscale, 2-dimensional arrays and fluidic or photonic systems may be defined. These rapid patterning techniques establish for the first time a link between computer-aided design and rapid processing of self-assembled nanostructures.

\section{INTRODUCTION}

Living systems exhibit form and function on multiple length scales, and the prospect of imparting life-like qualities to man-made materials has inspired many recent efforts to devise hierarchical materials assembly strategies. For example, Yang et al. ${ }^{11}$ grew surfactant-templated mesoporous silica ${ }^{[2]}$ on hydrophobic patterns prepared by micro-contact printing $\mu C P^{|3|}$. Trau et al. ${ }^{|4|}$ formed oriented mesoporous silica patterns, using a micro-molding in capillaries MIMIC technique $^{|3|}$, and Yang et al..$^{|5|}$ combined $M I M I C$, polystyrene sphere templating ${ }^{|6|}$, and surfactanttemplating to create oxides with three levels of structural order. Overall, great progress has been made to date in controlling structure on scales ranging from several nanometers to several micrometers. However, materials prepared have been limited to oxides with no specific functionality, whereas for many of the envisioned applications of hierarchical materials in microsystems, sensors, waveguides, photonics, and electronics, it is necessary to define both form and function on several length scales. In addition, the patterning strategies employed thus far require hours or even days for completion ${ }^{\{1,4,5\}}$. Such slow processes are inherently difficult to implement in commercial environments.

We have combined evaporation-induced (silica/surfactant) self-assembly $E I S A^{[7 \mid}$ with rapid prototyping techniques like pen lithography ${ }^{18,9]}$, ink-jet printing ${ }^{[10,11]}$, and dip-coating on micro-contact printed substrates to form hierarchically organized structures in seconds. In addition, by co-condensation of tetrafunctional silanes $\left(\mathrm{Si}(\mathrm{OR})_{4}\right)$ with tri-functional

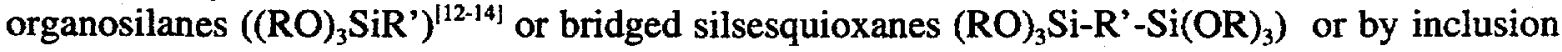


of organic additives, we have selectively derivatized the silica framework with functional $R$ ' ligands or molecules. The resulting materials exhibit form and function on multiple length scales: on the molecular scale, functional organic moieties are positioned on pore surfaces, on the mesoscale, mono-sized pores are organized into 1-, 2-, or 3-dimensional networks, providing size-selective accessibility from the gas or liquid phase, and on the macroscale, 2-dimensional arrays and fluidic or photonic systems may be defined.

\section{EXPERIMETAL}

Precursor solutions used as inks were prepared by addition of surfactants (cationic, CTAB; $\mathrm{CH}_{3}\left(\mathrm{CH}_{2}\right)_{15} \mathrm{~N}^{+}\left(\mathrm{CH}_{3}\right)_{3} \mathrm{Br}$ or non-ionic, Brij-56; $\mathrm{CH}_{3}\left(\mathrm{CH}_{2}\right)_{15}-\left(\mathrm{OCH}_{2} \mathrm{CH}_{2}\right)_{10}-\mathrm{OH}$ and Pluronic P123, $\left.\left.\mathrm{HO}\left(\mathrm{CH}_{2} \mathrm{CH}_{2} \mathrm{O}\right)_{20}\left(\mathrm{CH}\left(\mathrm{CH}_{3}\right) \mathrm{CH}_{2}\right) \mathrm{O}\right)_{70}-\left(\mathrm{CH}_{2} \mathrm{CH}_{2} \mathrm{O}\right)_{20}-\mathrm{H}\right)$, organosilanes (R'Si $(\mathrm{OR})_{3}$, see Table 1), or organic molecules (see Table 1) to an acidic silica sol prepared from TEOS $\left[\mathrm{Si}\left(\mathrm{OCH}_{2} \mathrm{CH}_{3}\right)_{4}\right](\mathrm{A} 2 * *)$. The acid concentration employed in the $\mathrm{A} 2 * *$ synthesis procedure was chosen to minimize the siloxane condensation rate, thereby promoting facile self-assembly during printing[20]. In a typical preparation, TEOS, ethanol, water and dilute $\mathrm{HCl}$ (mole ratios: 1:3.8:1:5 $\times 10^{-5}$ ) were refluxed at $60^{\circ} \mathrm{C}$ for $90 \mathrm{~min}$. The sol was diluted with 2 volumes of ethanol followed by further addition of water and $\mathrm{HCl}$. Organosilanes $\left(\mathrm{R}^{\prime}-\mathrm{Si}(\mathrm{OR})_{3}\right.$, where $\mathrm{R}^{\prime}$ is a nonhydrolyzable organic functional ligand) were added followed by surfactants and (optionally) organic additives (see Table 1). Surfactants were added in requisite amounts to achieve initial surfactant concentrations $c_{0}$ ranging from 0.004 to $0.23 \mathrm{M}\left(c_{o} \ll c m c\right)$. The final reactant molar ratios were: 1 TEOS : $22 \mathrm{C}_{2} \mathrm{H}_{5} \mathrm{OH}: 5 \mathrm{H}_{2} \mathrm{O}: 0.093-0.31$ surfactant : $0.039-0.8$ organosilanes : $2.6 \times 10^{-5}$ organic additives. For the ethylene-bridged silsesquioxane, $(\mathrm{RO})_{3} \mathrm{Si}-\mathrm{R}^{\prime}-\mathrm{Si}(\mathrm{OR})_{3}\left(\mathrm{R}^{\prime}=\right.$ $\mathrm{CH}_{2} \mathrm{CH}_{2}, \mathrm{R}=\mathrm{OC}_{2} \mathrm{H}_{5}$ ), the neat precursor was diluted in ethanol and mixed with $1-8 \mathrm{wt} \% \mathrm{CTAB}$ or Brij-56 surfactant followed by addition of an aqueous solution of $\mathrm{HCl}$. The final reactant molar ratios were: $\mathrm{Si}: \mathrm{EtOH}: \mathrm{H}_{2} \mathrm{O}: \mathrm{HCl}$ :surfactant $=1: 22: 5: 0.004: 0.054-0.18$. Co-hydrolysis of organosilanes with TEOS in the initial A2** sol preparation generally resulted in disordered worm-like mesostructures[21]. After pattern deposition and drying, the surfactant templates were selectively removed by calcination in a nitrogen atmosphere at a temperature sufficient to decompose the surfactant molecules $\left(-350^{\circ} \mathrm{C}\right)$ without degrading the covalently bound organic ligands R' (confirmed by ${ }^{29} \mathrm{Si}$ MAS NMR spectroscopy) or by solvent extraction.

\section{Patterning Procedures}

Micropen lithography was performed using a Model 400a micropen instrument purchased from Ohmcraft Inc., Pittsford, NY. The pen orifice was $50 \mu \mathrm{m}$ and the writing speed was 2.54 $\mathrm{cm} / \mathrm{s}$. The pattern was designed using AutoCAD 14 software.

Dip-coating of patterned (hydrophilic/hydrophobic) substrates was performed at a withdrawal speed of $7.6-51 \mathrm{~cm} / \mathrm{min}$ under ambient laboratory conditions. Hydrophilic/hydrophobic patterns were created by microcontact printing of hydrophobic, $\mathrm{n}$ octadecyltrichlorosilane $\left(\mathrm{CH}_{3}\left(\mathrm{CH}_{2}\right)_{17} \mathrm{SiCl}_{3}\right)$ self-assembled monolayers $S A M s^{[17]}$ on hydrophilic silicon substrates (hydroxylated native oxide) or by a technique involving electrochemical desorption of a hydroxyl-terminated $S A M$ prepared from 11-mercaptoundecanol $\left(\mathrm{HO}\left(\mathrm{CH}_{2}\right)_{11} \mathrm{SH}\right)$ from patterned, electrically isolated gold electrodes followed by immersion in a $1 \mathrm{mM}$ ethanolic solution of 1-dodecanethiol, $\mathrm{CH}_{3}\left(\mathrm{CH}_{2}\right)_{11} \mathrm{SH}^{[18]}$.

Ink jet printing was performed using a Model HP DeskJet $1200 \mathrm{C}$ printer purchased from Hewlett-Packard Co., San Diego, CA. The pattern was designed using Microsoft PowerPoint 98 software. 


\section{DISCLAIMER}

This report was prepared as an account of work sponsored by an agency of the United States Government. Neither the United States Government nor any agency thereof, nor any of their employees, make any warranty, express or implied, or assumes any legal liability or responsibility for the accuracy, completeness, or usefulness of any information, apparatus, product, or process disclosed, or represents that its use would not infringe privately owned rights. Reference herein to any specific commercial product, process, or service by trade name, trademark, manufacturer, or otherwise does not necessarily constitute or imply its endorsement, recommendation, or favoring by the United States Government or any agency thereof. The views and opinions of authors expressed herein do not necessarily state or reflect those of the United States Government or any agency thereof. 


\section{DISCLAIMER}

Portions of this document may be illegible in electronic image products. Images are produced from the best available original document. 
Table 1. Functional organosilanes and properties of resultant thin film mesophases

\begin{tabular}{|c|c|c|c|c|c|}
\hline & $\begin{array}{c}\text { Functional Silanes'/additives ' } \\
\text { R'-Si(OR) }_{3}\end{array}$ & Mesophase & $\begin{array}{l}\text { Pore Size } \\
(A)\end{array}$ & $\begin{array}{l}\text { Surface Area } \\
\left(\mathrm{m}^{2} / \mathrm{g}\right)\end{array}$ & Properties and Applications \\
\hline 1 & $\begin{array}{c}\mathrm{F}_{3} \mathrm{C}\left(\mathrm{CF}_{2}\right)_{3} \mathrm{CH}_{2} \mathrm{CH}_{2} \mathrm{Si}\left(\mathrm{OC}_{2} \mathrm{H}_{3}\right)_{3} \\
\text { Tridecafluoro-1,1,2,2- } \\
\text { tetrahydroctyltriethoxysilane (TFTS) }\end{array}$ & 3-dH & 25 & 850 & $\begin{array}{l}\text { Hydrophobic: } \\
\text { low k dielectrics }\end{array}$ \\
\hline 2 & $\begin{array}{c}\mathrm{HS}-\left(\mathrm{CH}_{2}\right)_{3} \mathrm{Si}\left(\mathrm{OCH}_{3}\right)_{3} \\
\text { Mercaptopropyltrimethoxysilane (MPS) }\end{array}$ & 3-dH & 25 & 1060 & Coupling of noble metals \\
\hline 3 & $\begin{array}{c}\mathrm{NH}_{2}-\left(\mathrm{CH}_{2}\right)_{3} \mathrm{Si}\left(\mathrm{OCH}_{3}\right)_{3} \\
\text { Aminopropyltrimethoxysilane (APS) }\end{array}$ & cubic & 22 & 750 & $\begin{array}{l}\text { Coupling of noble metals, dye, } \\
\text { and bioactive molecules }\end{array}$ \\
\hline 4 & Dye'-NH-(CH$)_{3} \mathrm{Si}\left(\mathrm{OCH}_{3}\right)_{3}$ & cubic & 21 & 545 & pH sensitive \\
\hline 5 & $-\mathrm{NH}_{2}\left(\mathrm{CH}_{2}\right)_{3} \mathrm{Si}\left(\mathrm{OC}_{2} \mathrm{H}_{3}\right)_{3}$ & 3-dH & 22 & 560 & $\begin{array}{l}\text { Chromophore; nonlinear optical } \\
\text { material }\left(\chi^{2}\right)\end{array}$ \\
\hline 6 & $\left(\mathrm{H}_{5} \mathrm{C}_{2} \mathrm{O}\right)_{3} \mathrm{SiCH}_{2} \mathrm{CH}_{2} \mathrm{Si}_{(}\left(\mathrm{OC}_{2} \mathrm{H}_{3}\right)_{3}$ & cubic & 40 & 430 & Low $\mathbf{k}$ dielectrics \\
\hline
\end{tabular}

'Pore size and surface area were determined from $\mathrm{N}_{2}$ sorption isotherms obtained at $-196^{\circ} \mathrm{C}$, using a surface acoustic wave (SAW) technique. Mass change due to nitrogen sorption was monitored ( $\sim 80 \mathrm{pg} \cdot \mathrm{cm}^{-2}$ sensitivity) as a function of nitrogen relative pressure. Pore size and surface area were determined from the isotherms using the BET equation and the BJH algorithm, respectively.

${ }^{\$}$ Functional groups are retained through selective surfactant removal during heat treatment in nitrogen. TGA and DTA were used to establish the appropriate temperature window enabling complete surfactant removal without silane decomposition

Additives investigated include rhodamine-B, cytochrome $c$ (from Fluka), oil blue N, disperse yellow 3 (from Aldrich), silver ions and silver nanoparticles.

* 4 was prepared by a conjugation reaction between a thin film mesophase containing $\mathbf{3}$ and the dye molecule (5,6-carboxyfluorecein, succinimidyl ester (5,6-FAM, SE) from Molecular Probes). 


\section{RESULTS AND DISCUSSION}

\section{Scheme 1}

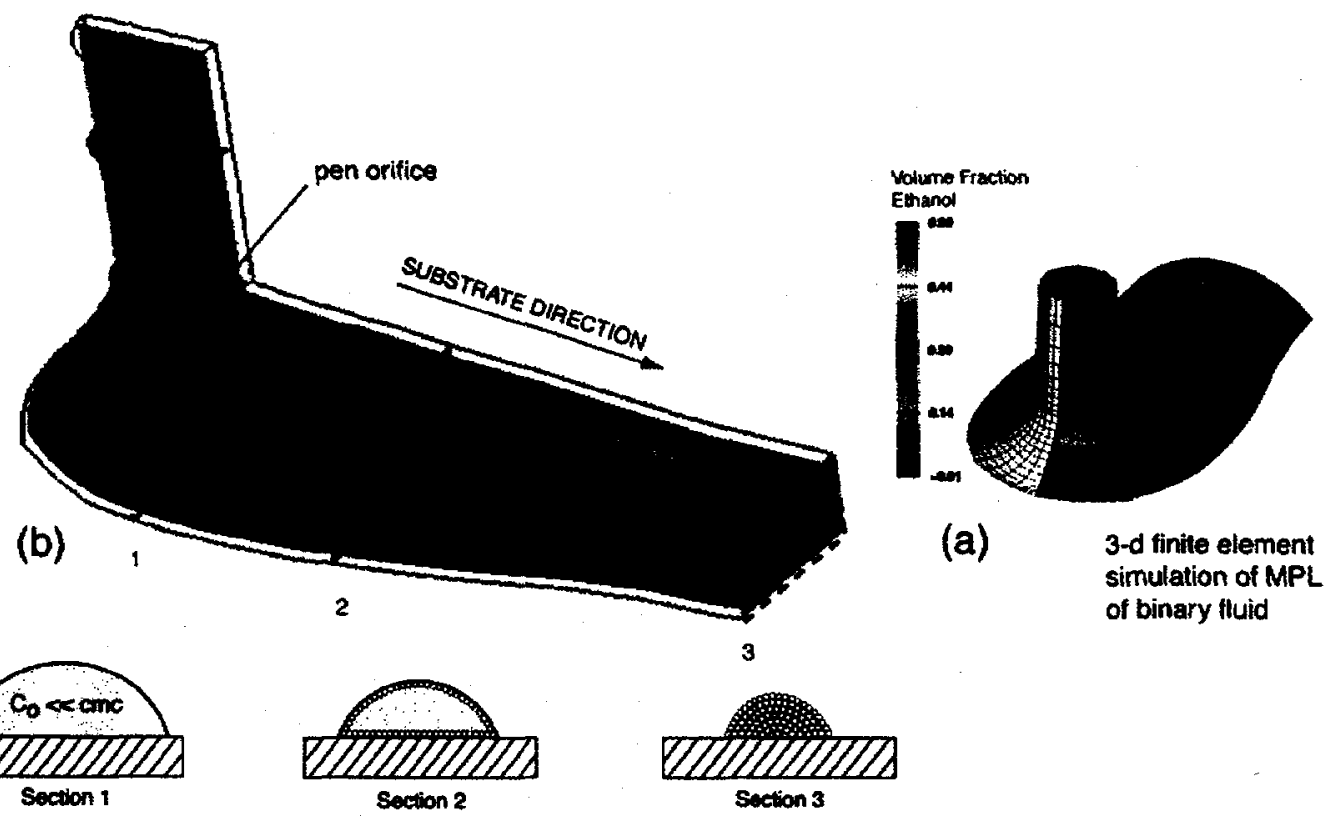

Figure 1. Scheme 1: micro-pen lithography $M P L$ of a surfactant-templated mesophase. a) Simulation of 3-D, binary fluid pattern dispensed on a flat substrate with substrate speed $=2.54$ $\mathrm{cm} / \mathrm{s}$ and fluid injection rate (inlet velocity) $=3.985 \mathrm{~cm} / \mathrm{s}$. Color contours represent evaporationinduced, 3-D gradients in alcohol-composition. Fluid was modeled as 54 volume $\%$ ethanol and 46 volume \% non-volatile phase with Reynolds number $=1.25$ and $\mathrm{Ca}=0.000833$. An ad hoc value of $45^{\circ}$ was chosen for the static contact angle. Note that this angle persists at all points on the dynamic contact line because of the dominance of surface tension at this low value of $\mathrm{Ca}$. b) The initially homogeneous sol metered on to the moving substrate experiences preferential evaporation of alcohol creating a complex 3-D (longitudinal and radial) gradient in the concentrations of water and non-volatile surfactant and silicate species. Progressive enrichment of silica and surfactant induces micelle formation and subsequent growth of silica/surfactant mesophases inward from solid-liquid and liquid-vapor interfaces as recently demonstrated for thin films 15 and aerosols 16 . The numerical method utilized for (a) and (b) consisted of a 3D finite element discretization of the Navier Stokes equations augmented with a three dimensional boundary-fitted mesh motion algorithm to track the free surface 25,26 . Special relations at the 3D dynamic wetting line were also applied.

Scheme 1 (Figure 1) schematically illustrates direct writing of a mesoscopically ordered nanostructure, using micro-pen lithography $M P L^{[9]}$ For ink we use homogeneous solutions of TEOS, ethanol, water, surfactant, acid, and (optionally) organosilanes and other organic ingredients (see Table 1). These solutions are prepared with an initial surfactant concentration $c_{o}$ less than the critical surfactant concentration $c m c$ and an acid concentration designed to minimize the siloxane condensation rate, thereby enabling facile silica/surfactant self-assembly within the brief time span of the writing operation. As the ink is metered onto the surface, 
preferential ethanol evaporation causes enrichment of water, surfactant, and silica, establishing a 3-D (longitudinal and radial) gradient in their respective concentrations (Figure 1). Where $\mathrm{cmc}$ is exceeded, cooperative silica/surfactant self-assembly creates micelles. Further evaporation, of predominantly water, promotes the continuous self-organization of micelles into silica/surfactant liquid crystalline mesophases. As demonstrated previously for $E I S A$ of films ${ }^{[15\rfloor}$ and aerosols ${ }^{[19]}$, liquid crystalline domains are nucleated by incipient surfactant monolayers formed at solidliquid $^{\mid 20,21]}$ and liquid-vapor interfaces ${ }^{|22|}$ (at $c<c m c$ ) and grow inward as evaporation proceeds.
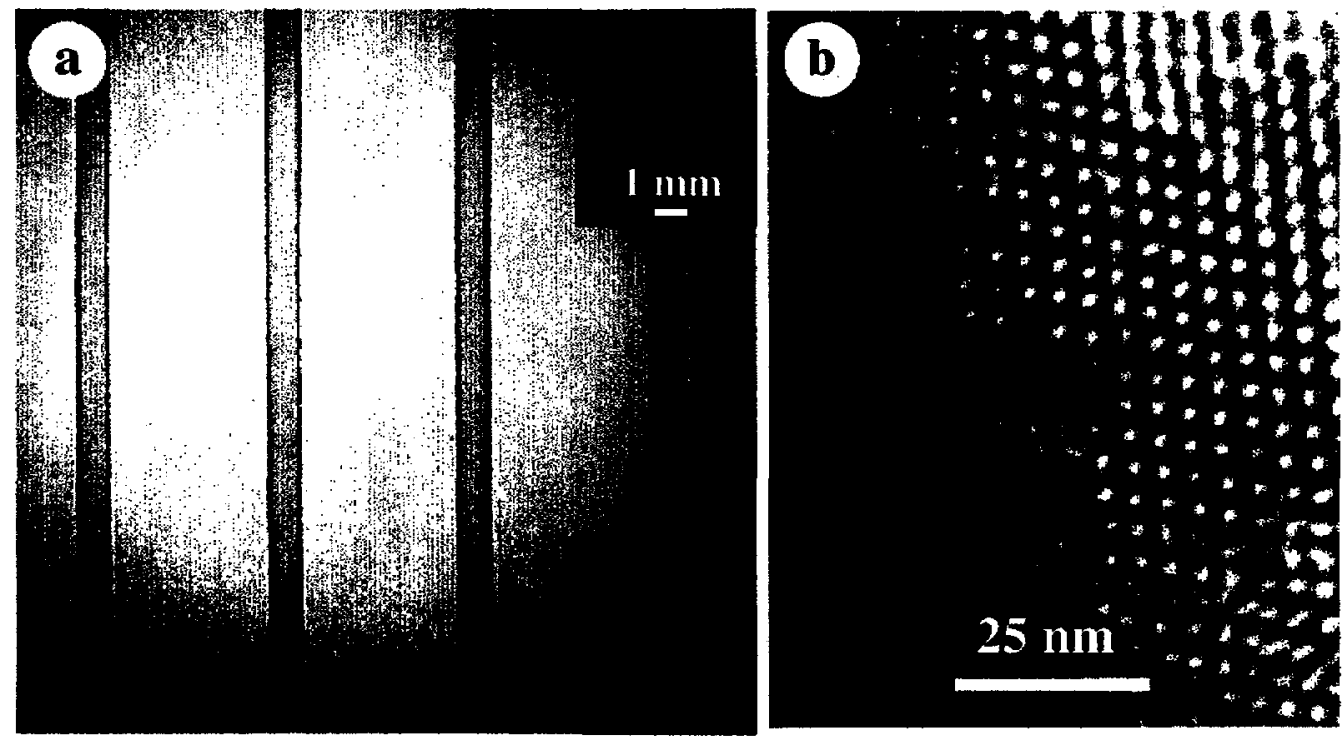

Figure 2. Meandering patterned mesophase created by $M P L$. a) Optical micrograph of patterned rhodamine-B containing silica mesophase deposited on an oxidized [100]-oriented silicon substrate at a speed of $2.54 \mathrm{~cm} / \mathrm{s}$. Inset is a fluorescence image of rhodamine-B emission acquired through a $610-\mathrm{nm}$ band pass filter, demonstrating retention of rhodamine-B functionality. b) Representative TEM micrograph of a fragment of the patterned rhodamine-B containing film corresponding to a [110]-oriented cubic mesophase with lattice constant $a=$ 10.3-nm. The sol was prepared by adding $0.01 \mathrm{wt} \%$ rhodamine-B to a silica $/ 4 \mathrm{wt} \% \mathrm{Brij}-56 \mathrm{sol}$.

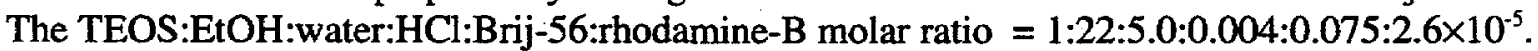

Figure 2a shows a meandering macroscopic pattern formed in several seconds by $M P L$ of a rhodamine B-containing solution on a hydrophilic surface (hydroxylated native oxide of $\langle 100\rangle$ silicon). The inset in Figure 2a shows the corresponding fluorescence image of several adjacent stripes, and the TEM micrograph (Figure $2 \mathrm{c}$ ) reveals the ordered pore structure characteristic of a cubic thin film mesophase. The MPL line width can vary from micrometers to millimeters. It depends on such factors as pen dimension ${ }^{|8|}$, wetting characteristics, evaporation rate, capillary number ( $\mathrm{Ca}=$ ink viscosity $\mathrm{x}$ substrate speed/surface tension) and ratio of the rates of ink supply and withdrawal (inlet velocity/substrate velocity). The effect of wetting has been demonstrated by performing $M P L$ on substrates pre-patterned with hydrophobic, hydrophilic or mixed SAMs. Generally, line widths are reduced by increasing the contact angle and by reducing the inlet/substrate velocity ratio. The conditions providing the minimum stable line width are bounded by a regime of capillary instability - we anticipate that this instability could be exploited to create periodic arrays of dots. 


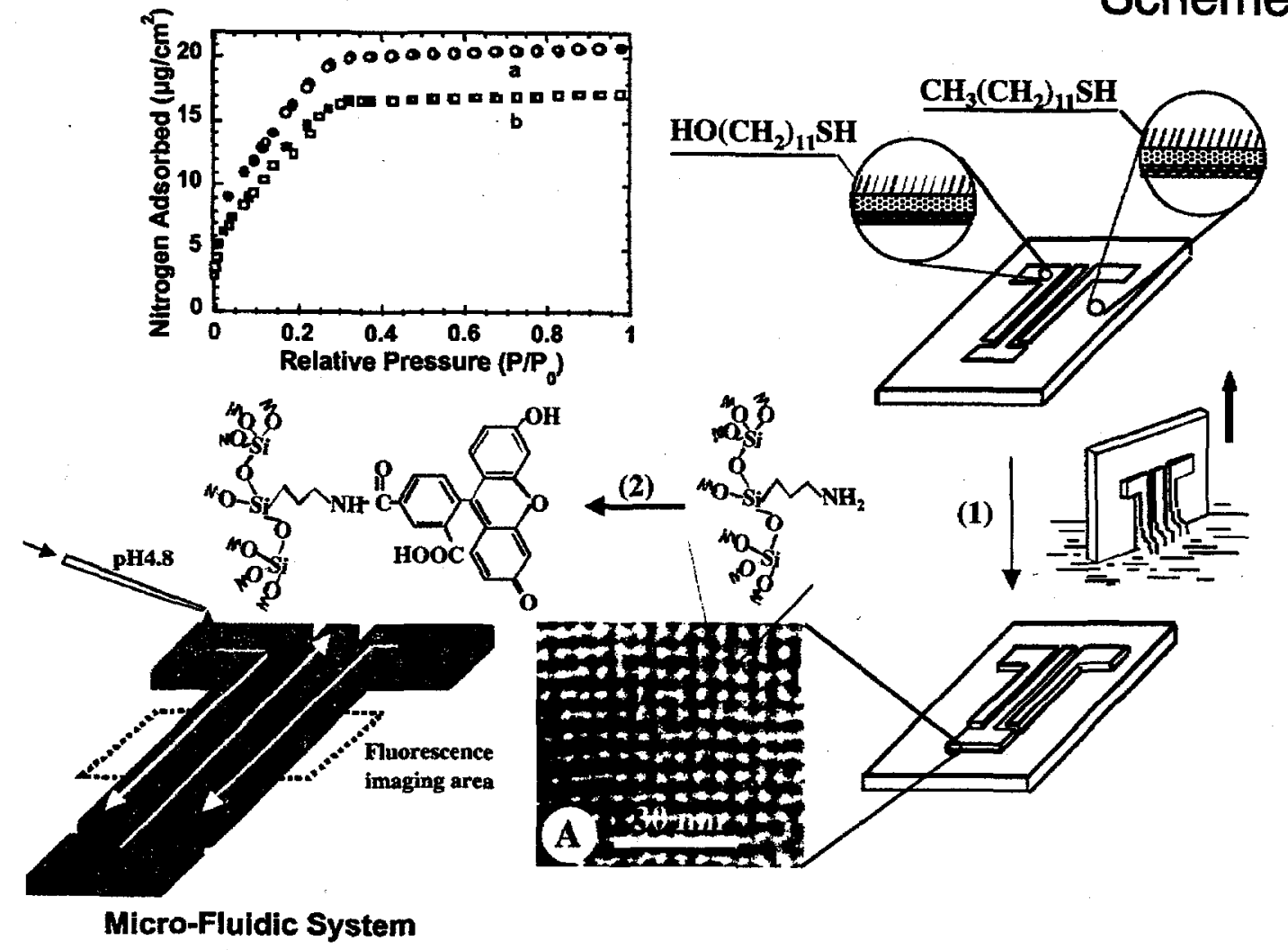

Scheme 2

Figure 3. Scheme 2: Patterned functional mesostructure formed by selective de-wetting. Using micro-contact printing or electrochemical desorption techniques, substrates are prepared with patterns of hydrophilic, hydroxyl-terminated SAMs and hydrophobic methyl-terminated SAMs. Preferential ethanol evaporation during dip-coating (1), causes water enrichment and selective de-wetting of the hydrophobic SAMs. Correspondingly film deposition occurs exclusively on the patterned hydrophilic SAMs. The sol was prepared by adding aminopropyltrimethoxysilane $\left(\mathrm{NH}_{2}\left(\mathrm{CH}_{2}\right)_{3} \mathrm{Si}\left(\mathrm{OCH}_{3}\right)_{3}\right.$, APS $)$ to a silica/4wt\% Brij-56 sol, resulting in a final molar ratio TEOS:APS:EtOH:water:HCl:Brij-56 = 1:0.8:22:5.0:0.011:0.075. Selective de-wetting followed by calcination results in a patterned, amine-functionalized, cubic mesoporous film as is evident from the plan-view TEM micrograph (Inset A), showing a [100]-oriented cubic mesophase with $a=10.3-\mathrm{nm}$ and nitrogen adsorption-desorption isotherm (Inset B, curve a) acquired for the thin film specimen using a surface acoustic wave 22 (SAW) technique. The dye conjugation reaction (2) was conducted by immersion in a $0.00002 \mathrm{mM}$ solution of 5,6-FAM, SE (Table 1) prepared in dimethylsulfoxide (DMSO) followed by exhaustive, successive washing in DMSO, ethanol, and water. The SAW-based nitrogen adsorption-desorption isotherm of the dye-conjugated mesoporous film is shown in Inset B, curve $b$, confirming its pore accessibility. BET analyses of the sorption isotherms indicate that the dye conjugation reaction reduces the surface area from 750 to $545 \mathrm{~m}^{2} / \mathrm{g}$ and the hydraulic radius from 2.2 to $2.1-\mathrm{nm}$, but pore accessibility is completely retained as evident from combined TEM, SAW, and fluorescent-imaging results (Figure 4a).

The advantages of $M P L$ are that we can use computer-aided design to define any arbitrary 2-D pattern and that we can use any desired combination of surfactant and functional silane as ink to selectively define different functionalities at different locations. However $M P L$ is a serial 
technique. In situations where it is desirable to create an entire pattern with the same functionality, it would be preferable to employ a parallel technique in which the deposition process occurred simultaneously in multiple locations. Scheme $\underline{2}$ (Figure 3) illustrates a rapid, parallel patterning procedure, dip-coating on patterned SAMs. This procedure uses micro-contact printing ${ }^{[23]}$ or electrochemical patterning ${ }^{|18|}$ of hydroxyl- and methyl-terminated SAMs to define hydrophilic and hydrophobic patterns on the substrate surface. Then using homogenous solutions identical to those employed for $M P L$, preferential ethanol evaporation during dipcoating enriches the depositing film in water, causing selective de-wetting of the hydrophobic regions. In this fashion, lines, arrays of dots, or other arbitrary shapes can be deposited on hydrophilic patterns in seconds. As described for $M P L$, further evaporation accompanying the dip-coating operation induces self-assembly of silica/surfactant mesophases.
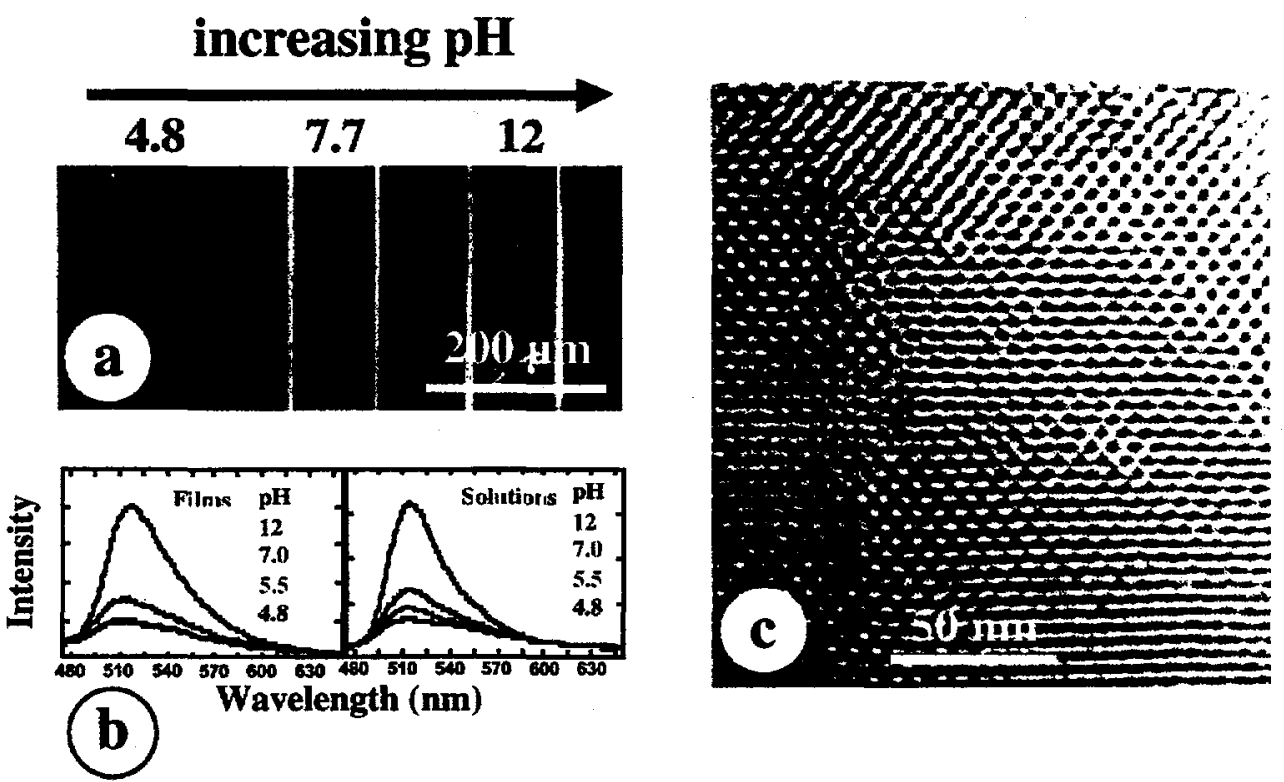

Figure 4. Patterned pH-sensitive fluidic system. a) Fluorescence image of three adjacent 5,6FAM, SE-conjugated pore channel networks after introduction of aqueous solutions prepared at $\mathrm{pH} 4.8,7.7$, or 12.0. Patterned dye-conjugated thin film mesophases were prepared according to Scheme 2 (Figure 3). Aqueous solutions of varying $\mathrm{pH}$ were introduced on the terminal pads (Figure 3) and transported into the imaging cell by capillary flow. Image was acquired using a Nikon Diaphot 300 inverted microscope and 520-nm band pass filter. b) Fluorescence spectra of 5,6-FAM, SE-conjugated mesoporous films upon exposure to aqueous solutions of $\mathrm{pH} 4.8,7.7$, and 12.0. Shown for comparison are fluorescence spectra of 0.1 micromolar solutions of 5,6-

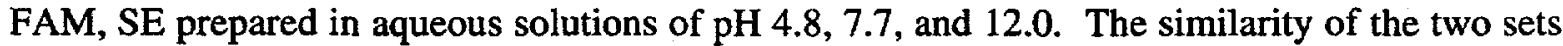
of spectra confirms the maintenance of dye functionality upon conjugation within the mesoporous channel system. c) Cross-sectional TEM micrograph of the patterned, dyeconjugated thin film mesophase, providing evidence of the 3-D pore channel network.

The patterned dip-coating procedure may be conducted with organic dyes or functional silanes (see Table 1). Scheme $\underline{2}$ illustrates patterned deposition of a propyl-amine derivatized cubic mesophase followed by a conjugation reaction with a $\mathrm{pH}$-sensitive dye, 5,6carboxyfluorescein, succinimidyl ester (5,6-FAM, SE). The uniform continuous porosity of the amine-derivatized and dye-conjugated films is confirmed by TEM and surface acoustic wave (SAW)-based nitrogen sorption isotherms ${ }^{|24|}$ of the corresponding films deposited on SAW 
Figure 5. Patterned dot arrays created by ink-jet printing. a) Optical micrograph of dot array created by ink jet printing of standard ink (from Hewlett-Packard Co., San Diego, CA) on a non-adsorbent surface. b) Optical micrograph of an array of hydrophobic, mesoporous silica dots created by evaporation-induced silica/surfactant self-assembly during $I J P$ on an oxidized [100]-oriented silicon substrate followed by calcination.

c) Representative TEM micrograph of a dot fragment prepared as in (b). The sol was prepared with molar ratio TEOS:TFTS (1):EtOH: water:HCl:Brij-56= 1:0.05:22.0:5.0:0.004:0.075. The dot pattern used in a) and b) was designed using Microsoft PowerPoint 98 software. The printing rate was approximately $80 \mathrm{dots} / \mathrm{s}$ and printer resolution 300 dots/inch. The resolution achieved compared to standard ink and our ability to selectively functionalize the ink suggest applications in display technologies.
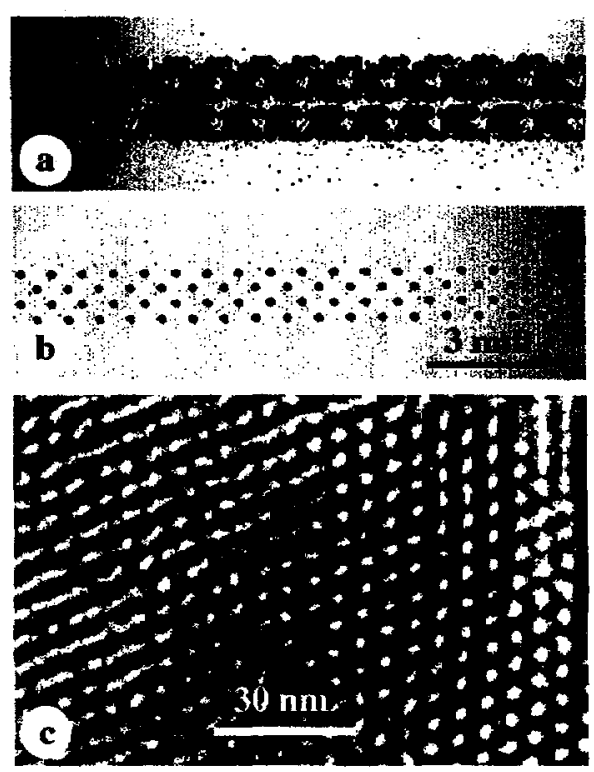

substrates (Figure 4). The reduction in film porosity after dye conjugation reflects the volume occupied by the attached dye moieties. The patterned, functional array can be used to monitor the $\mathrm{pH}$ of fluids introduced at arbitrary locations and transported by capillary flow into the imaging cell. Figure $4 \mathrm{a}$ shows the fluorescence image of an array contacted with three different aqueous solutions prepared at $\mathrm{pH} 4.8,7.7$, and 12.0. Figure $4 \mathrm{~b}$ shows the corresponding emission spectra and provides a comparison with solution data. In combination, the fluorescence image (Fig. 4a) and plan-view and cross-sectional TEM micrographs (Figures 3 and 4c) of the dye-conjugated film demonstrate the uniformity of macro- and mesoscale features achievable by this evaporation-induced, de-wetting and self-assembly route. In comparison, films formed by nucleation and growth of thin film mesophases on patterned SAMs ${ }^{\mid 1 !}$ are observed to have nonhomogeneous, globular morphologies.

Finally we can create patterned nanostructures by combining EISA with a variety of aerosol processing schemes. For example, Figure 5 compares an optical micrograph of a macroscopic array of spots formed by ink jet printing $I J P^{10,11}$ on a silicon wafer with $I J P$ of standard ink on a non-adsorbent surface. The IJP process dispenses the ink (prepared as for $M P L$ ) as monosized, spherical aerosol droplets. Upon impaction the droplets adopt a new shape that balances surface and interfacial energies. Accompanying evaporation creates within each droplet a gradient in surfactant concentration that that drives radially-directed silica/surfactant self-assembly inward from the liquid-vapor interface ${ }^{|19|}$. The inset in Figure 5 shows a representative TEM micrograph of a hydrophobic, fluoroalkylated silica mesophase formed by $I J P$. The resolution achieved compared to standard ink and our ability to selectively functionalize the ink suggest applications in display technologies. Continuous, nanostructured lines are created by coalescence of overlapping droplets. Patterns may also be created by aerosol deposition through a mask or by aerosol deposition on patterned hydrophilic/hydrophobic surfaces (H. Fan, Y. Lu, and A. Stump, unpublished).

CONCLUSIONS We have combined evaporation-induced (silica/surfactant) self-assembly EISA with rapid prototyping techniques like pen lithography, ink-jet printing, and dip-coating on micro-contact printed substrates to form hierarchically organized structures in seconds. In 
addition, by co-condensation of tetrafunctional silanes ( $\left.\mathrm{Si}(\mathrm{OR})_{4}\right)$ with tri-functional organosilanes $\left((\mathrm{RO})_{3} \mathrm{SiR}^{\prime}\right)$ or by inclusion of organic additives, we have selectively derivatized the silica framework with functional $R^{\prime}$ ligands or molecules. The resulting materials exhibit form and function on multiple length scales and multiple locations.

ACKNOWLDGEMENTS : This work was supported by the US Department of Energy Basic Energy Sciences Program, the Sandia National Laboratories Laboratory-Directed Research and Development Program, and the Defense Advanced Research Projects Agency Bio-Weapons Defense Program. The authors also thank Mr. Pin Yang, Mr. Scott Reed for technical assistance with micro-pen lithography, and Dr. Tom Baer and Dr. Randy Schunk for 3D simulation of micropen. TEM investigations were performed in the Department of Earth and Planetary Sciences at the University of New Mexico. Sandia is a multiprogram laboratory operated by Sandia Corporation, a Lockheed-Martin Company, for the U.S. DOE under Contract DE-AC0494AL85000.

\section{References}

[1] H. Yang, N. Coombs, G. A. Ozin, Adv. Mater. 1997, 9, 811.

[2] C. Kresge, M. Leonowicz, W. Roth, C. Vartuli, J. Beck, Nature 1992, 359, 710.

[3] Y. Xia, G. M. Whitesides, Angew. Chem. Int. Ed. 1998, 37, 550.

[4] M. Trau, N. Uao, E. Lim, Y. Xia, G. M. Whitesides, I. A. Aksay, Nature 1997, $390,674$.

[5] P. Yang, T. Deng, D. Zhao, P. Feng, D. Pine, B. F. Chmelka, G. M. Whitesides, G. D. Stucky, Science 1998, 282, 2244.

[6] M. Antonietti, B. Berton, C. Goltner, H. P. Hentze, Adv. Mater. 1998, 10, 154.

[7] c. J. Brinker, Y. Lu, A. Sellinger, H. Fan, Adv. Mater. 1999, 11, 579.

[8] R. D. Piner, J. Zhu, F. Xu, S. Hong, C. A. Mirkin, Science 1999, $283,661$.

[9] P. Yang, D. Dimos, M. A. Rodriguez, R. F. Huang, S. Dai, D. Wilcox, Mat. Res. Soc. Symp. Proc. 1999, 542, 159.

[10] S.-C. Chang, J. Liu, J. Bharathan, Y. Yang, J. Onohara, J. Kido, Adv. Mater. 1999, 11, 734.

[11] D. Pede, G. Serra, D. De Rossi, Mat. Sci. and Eng. 1998, C5, 289.

[12] S. L. Burkett, S. D. Sims, S. Mann, Chem. Commun. 1996, 1367.

[13] C. E. Fowler, S. L. Burkett, S. Mann, Chem. Commun. 1997, 1769.

[14] M. H. Lim, C. F. Blanford, A. Stein, J. AM. Chem. Soc. 1997, 119, 4090.

[15] Y. Lu, R. Ganguli, C. A. Drewien, M. T. Anderson, C. J. Brinker, W. L. Gong, Y. X. Guo, H. Soyez, B. Dunn, M. H. Huang, J. I. Zink, Nature 1997, 389, 364.

[16] P. T. Tanev, T. J. Pinnavaia, Science 1995, 267, 865.

[17] C. D. Bain, E. B. Troughton, Y.-T. Tao, J. Evall, G. M. Whitesides, R. G. Nuzzo, J. Am. Chem. Soc. 1989, 111, 321.

[18] L. M. Tender, W. R.L., H. Fan, G. P. Lopez, Langmuir 1996, 12, 5515.

[19] Y. Lu, H. Fan, A. Stump, T. L. Ward, T. Reiker, C. J. Brinker, Nature 1999, 398, 223.

[20] I. A. Aksay, Science 1996, 273, 892.

[21] H. Yang, A. Kuperman, N. Coombs, S. Mamiche-Afara, G. A. Ozin, Nature 1996, 379, 703.

[22] H. Yang, N. Coombs, I. Sokolov, G. A. Ozin, Nature 1996, 381, 589.

[23] J. L. Wilbur, A. Kumar, H. A. Biebuyck, E. Kim, G. M. Whitesides, Nanotechnology 1996, 7,452 .

[24] G. C. Frye, A. J. Ricco, S. J. Martin, C. J. Brinker, in Better Ceramics Through Chemistry III, Vol. 121 (Eds.: C. J. Brinker, D. E. Clark, D. R. Ulrich), Mat. Res. Soc., Reno, Nevada, 1988 , pp. 349. 